\title{
Highly-porous hierarchical SiC structures obtained by filament printing and partial sintering
}

\author{
A. Gómez, J. J. Moyano, B. Román-Manso ${ }^{\S}$, M. Belmonte, P. Miranzo, M. I. Osendi* \\ Instituto de Cerámica y Vidrio, CSIC. Campus Cantoblanco. 28049 Madrid. Spain
}

\begin{abstract}
Three-dimensional (3D) porous silicon carbide ( $\mathrm{SiC}$ ) structures with total porosity in the range of $64-85 \%$ are achieved from nanosized SiC powders by filament printing and partial sintering in a spark plasma sintering (SPS) furnace. The effects of the SPS temperature $\left(1500\right.$ and $\left.1700^{\circ} \mathrm{C}\right)$ and the addition of oxide sintering aids (7 wt. \% $\mathrm{Y}_{2} \mathrm{O}_{3}+\mathrm{Al}_{2} \mathrm{O}_{3}$ ) on the porosity of the scaffolds are quantitatively compared. More specifically, hierarchical porosity consisting in the presence of meso-pores $(<50 \mathrm{~nm})$ in the struts and macro-pores (in the range of 500-700 $\mu \mathrm{m}$ ) defined by the patterned structure is demonstrated for the $1500{ }^{\circ} \mathrm{C}$ SPS treatment. The strength of the structures is analyzed as a function of the density as well as the cooling profiles once subjected to rapid heating under a direct flame. By this simple method, an adaptable family of robust light 3D SiC structures with hierarchical porosity is accomplished.
\end{abstract}

\section{Introduction}

Stable, strong, and temperature-resistant porous ceramics are attractive materials that show a wide scope of potential uses, such as for heat dissipation, filters, sensors, microfluidics, solar energy absorption or catalysis [1]. In particular, SiC-type ceramics are prominent for those uses and, actually, a variety of methods for creating $\mathrm{SiC}$ or SiOC porous ceramics have been reported [2]. These methods include partial sintering, reaction-infiltration of different types of carbon preforms with molten $\mathrm{Si}$, the sacrificial

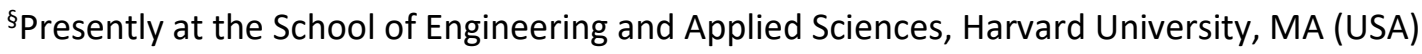

* Corresponding author E-mail address: miosendi@icv.csic.es (M. Isabel Osendi) 
template and replica methods, and the pyrolysis of polymer precursors. The porosity level normally varies in the range of $30-90 \%$ and pore sizes can fluctuate from microto meso- and macro-pores depending on the selected processing route [2-3]. Partial sintering stands out as one of the simplest processes to produce macro-porous (100 nm $10 \mathrm{~mm}$ ) ceramics, where the total porosity as well as the pore size are controlled by both the initial grain size and the degree of sintering [3, 4]. Actually, it has been reported that the raw powder size should be about 2-5 times larger than the desired pore size when using the partial sintering route [4]. For example, membrane supports of $\mathrm{SiC}$ with $40 \%$ porosity and pores in the range $80-100 \mathrm{~nm}$ were achieved by partially sintering $\mathrm{SiC}$ powders of $\sim 100 \mathrm{~nm}$ of size, at temperatures in the scale of $1500-1800{ }^{\circ} \mathrm{C}$, using a conventional graphite furnace and a small amount of $\mathrm{Al}_{2} \mathrm{O}_{3}$ as sintering aid [5].

The option of using three-dimensional (3D) printing to create macro-porosity offers the advantage of controlling the shape and size of the large pore or open cells defined by the architecture. In particular, the direct ink writing (DIW) of SiC scaffolds, containing between 7 and 20 wt.\% of oxide sintering aids (a $\mathrm{Y}_{2} \mathrm{O}_{3}+\mathrm{Al}_{2} \mathrm{O}_{3}$ mixture), and subsequent densification by spark plasma sintering (SPS) at temperatures of $1700-1800{ }^{\circ} \mathrm{C}$ [6-7], was effective for building spanned structures. These structures had $\sim 60 \mathrm{vol} . \%$ of macro-pores defined by the woodpile structure, but the skeletons were practically dense,--with close porosity of $\sim 1 \%$ when employing micron size $\mathrm{SiC}$ raw powders and $\sim 10 \%$ for nano-sized powders.

On the other hand, as Flek et al. pointed out [8], introducing a certain structural hierarchy in engineering ceramics by designing multi-scale lattice materials, as nature often does, produces low stiffness and bending-dominated architectures. Structuring at different scales can be beneficial for different functionalities as well; for instance, in the case of silica-based biomaterials, the tailoring of the scaffolds' hierarchy -with different 
pore size levels and precise architectures- was crucial for the bone tissue regeneration [9]. In the case of zeolites, the hierarchical structure of porosity at three levels (macromeso-micro) has been proved to favor their catalytic activity [10]. More recently, enhanced mechanical specific strength was confirmed for alumina ceramics having ordered porosity across multiple length scales, which was achieved by combining DIW and emulsion/foam templating [11]. Similarly, high specific compressive strength was demonstrated in hierarchically structured $\mathrm{Al}_{2} \mathrm{O}_{3}$ ceramics but with fully-open porosity. In this case, structures were developed by employing capillary suspensions and DIW [12]. Using also a DIW method, researchers succeeded in making porosity-tunable 3D hierarchical architectures of $\mathrm{TiO}_{2}$ with the aim of building 3D micro-leaves for artificial photosynthesis purposes, exhibiting microporous architectures comparable to those of natural leaves [13].

Focusing on lightweight $\mathrm{SiC}$ ceramics with hierarchical porosity, it is worth mentioning a work about $\mathrm{SiC}$ foams covered with entangled silicon oxynitride nanowires grown on the surface by a catalytic process [14]. Using a different approach, SiC foams with two scales of macro-porosity (in the ranges of 1-10 $\mu \mathrm{m}$ and $15-50 \mu \mathrm{m}$, respectively) were achieved by freeze casting of SiC-fibers, which showed higher strengths than analogous but unordered porous aerogels [15]. However, so far there have been no attempts to build hierarchically structured porous SiC materials by DIW, except for previous work by some of the current authors [16]. In that work, a certain hierarchy of porosity was granted by growing aligned multiwall carbon nanotubes -using chemical vapor deposition methods- on the filaments of the $3 \mathrm{D}$ printed $\mathrm{SiC}$ scaffolds, which produced both decreased macropores size in the structures and smaller size porosity in the outer nanotubes mat. 
In the present work, we investigate the use of DIW and partial sintering for creating SiC scaffolds with a hierarchical pore structure, in particular, with small pores distributed in the struts and large macro-pores defined by the printed structure. The use of the partial sintering method with the SPS furnace offers additional advantage such as rapid heating and short sintering schedules, thus reducing high temperature stability issues. Accordingly, light cellular $\mathrm{SiC}$ materials (up to $85 \%$ porosity) with ordered porosity including multiscale porosity, such as meso-pores $(\sim 30 \mathrm{~nm})$ in the struts and macropores (in the hundreds of a $\mu \mathrm{m}$ scale) defined by the logpile structure- have been achieved via filament printing using nano-sized $\mathrm{SiC}$ powders by tuning the amount of oxide sintering aids and the sintering temperature. These $\mathrm{SiC}$ structures are quite strong despite their high porosity and demonstrate considerable temperature and corrosion resistances, which make them very attractive for a wide range of applications, including catalytic supports, filters, heat dissipation or radiant gas burners [17-19].

\section{Experimental part}

The starting $\mathrm{SiC}$ powders were nano-sized $\beta-\mathrm{SiC}$ (NanoAmor, average size $\mathrm{d}_{50}=50 \mathrm{~nm}$, polytype $3 \mathrm{C}$ ). The oxygen content of these $\beta$-SiC powders is $\sim 5 \mathrm{wt} \%$. Two batches of powder were utilized in the present work: i) the as-purchased raw $\beta$-SiC powder, whose resulting inks were subsequently labeled as N0 (plain SiC), and ii) a SiC-based composition containing 2 wt. $\%$ of $\mathrm{Al}_{2} \mathrm{O}_{3}\left(\mathrm{~d}_{50}=0.37 \mu \mathrm{m}, \mathrm{CR}-15\right.$; Baikalox, France $)$ and 5 wt. $\%$ of $\mathrm{Y}_{2} \mathrm{O}_{3}$ powders $\left(\mathrm{d}_{50}=2.09 \mu \mathrm{m}\right.$, AT; H.C.Starck, $\left.\mathrm{GmbH}\right)$ as sintering additives, next labeled as N7 (7 wt. \% of sintering aids). This powder composition was prepared by mixing/milling all powders in a Teflon lined attritor container (during $2 \mathrm{~h}$ ) using $\mathrm{Al}_{2} \mathrm{O}_{3}$ balls and alcohol media; afterwards, the solvent was removed in a rotatorevaporator. Inks for DIW were prepared by dispersing the powders in aqueous solutions, containing both high molecular weight and low molecular weight 
polyethylenimine, PEI, (H-PEI, Mw = $25000 \mathrm{~g} \cdot \mathrm{mol}^{-1}$, 99 wt.\% concentration, L-PEI, $\mathrm{Mw}=2000 \mathrm{~g} \cdot \mathrm{mol}^{-1}, 50 \mathrm{wt} . \%$ concentration; Aldrich Chemical Co. USA). Powders were gradually added and homogenized in a planetary centrifugal mixer (AR-250; Thinky Company, USA) for $1 \mathrm{~min}$. Methylcellulose (Methocel F4M, Mw = $3500 \mathrm{~g} \cdot \mathrm{mol}^{-}$ 1, 5 wt.\% concentration; Dow Chemical Company, USA) was used to prevent phase separation during ink extrusion.

The viscosity of the slurries was determined with a rheometer (CVO $100 \mathrm{D}$, Bohlin Instruments, UK) equipped with cone-and-plate geometry ( $4^{\circ}$ cone angle) that was covered with a fitting tool to reduce evaporation. The apparent viscosity ( $\left.\eta_{\text {app }}\right)$ of the inks was measured as a function of increasing shear rate in the range $0.01-150 \mathrm{~s}^{-1}$. Oscillatory tests were also done at $1 \mathrm{~Hz}$ to determine the two terms of the complex shear modulus, i.e. the storage $\left(\mathrm{G}^{\prime}\right)$ and loss moduli $\left(\mathrm{G}^{\prime \prime}\right)$ of each ink. Rectangular lattices with a logpile structure were prototyped with a designing software (RoboCAD 4.0, 3-D Inks LLC, Stillwater, OK). Syringes of $3 \mathrm{~cm}^{3}$ (EFD Inc., USA) were filled with the corresponding ink that was extruded through the nozzle with diameter of $330 \mu \mathrm{m}$ (Precision Tips; EFD Inc.) using a custom three-axis robocasting system (A-3200, 3-D Inks LLC). Printing was done at room temperature on flat alumina substrates. The ink feeding speed was automatically controlled at a constant volumetric flow rate of $0.25 \mathrm{D}^{2} \mathrm{v}$, where $\mathrm{D}$ is the inner diameter of the nozzle and $\mathrm{v}$ is the table speed $\left(10 \mathrm{~mm} \cdot \mathrm{s}^{-1}\right.$ for the present structures). Square lattices of $\sim 13 \times 13 \times 11 \mathrm{~mm}^{3}$ with $1 \mathrm{~mm}$ span (green state) between filaments were assembled by depositing a linear array of parallel filaments, layer-by-layer in such a way that they are orthogonal in adjacent layers. Air-dried samples were put in a box furnace at $600{ }^{\circ} \mathrm{C}$ for $2 \mathrm{~h}$ in air to burn out the organic additives and, afterwards, treated in the SPS (Dr. Sinter, SPS-510CE; Fuji Electronic Industrial Co., Ltd, Japan). The SPS tests were carried out at two different 
temperatures, 1500 and $1700^{\circ} \mathrm{C}$, for $5 \mathrm{~min}$ in $\mathrm{Ar}$ atmosphere at $6 \mathrm{~Pa}$ of pressure, using a purposely designed graphite die tool to avoid the collapse of the structures when a minimum contact load was applied to the die. Four types of materials were correspondingly obtained, namely N0-1500, N0-1700, N7-1500 and N7-1700, in reference to the ink compositions (N0, N7) and their corresponding sintering temperatures $\left(1500\right.$ and $\left.1700{ }^{\circ} \mathrm{C}\right)$.

Bulk density ( $\rho_{\text {bulk }}$ ) of the structures was determined by weighing and measuring the scaffolds. Dimension and weight changes of the ceramic lattices after the different sintering runs were also measured. The apparent density of the as-sintered structures was measured by the water immersion method, calculated as $\rho_{\text {app }}=\left[\mathrm{m} /\left(\mathrm{m}-\mathrm{m}_{\mathrm{H}_{2} \mathrm{O}}\right)\right] \cdot \rho_{\mathrm{H}_{2} \mathrm{O}}$, where $m, m_{H_{2} \mathrm{O}}$ and $\rho_{\mathrm{H}_{2} \mathrm{O}}$ are the weight of the dried specimen, the weight of the submerged specimen and the density of water, respectively. The true density that corresponds to the strut density was equally obtained by $\rho_{\text {strut }}=\left[\mathrm{m} /\left(\mathrm{m}_{\mathrm{sat}}-\mathrm{m}_{\mathrm{H}_{2} \mathrm{O}}\right)\right]$. $\rho_{\mathrm{H}_{2} \mathrm{O}}$, where $m_{\text {sat }}$ is the weight of the water saturated specimen. Theoretical densities were estimated, according to the composition and theoretical densities of the original powders $\left(\rho_{\mathrm{SiC}}=3.21 \mathrm{~g} \cdot \mathrm{cm}^{-3}, \rho_{\mathrm{Y} 2 \mathrm{O} 3}=5.01 \mathrm{~g} \cdot \mathrm{cm}^{-3}, \rho_{\mathrm{Al} 2 \mathrm{O} 3}=3.97 \mathrm{~g} \cdot \mathrm{cm}^{-3}\right)$.

The crystalline phases were analyzed by X-ray diffraction procedures on ground samples (XRD; Siemens D5000, Munich, Germany). The specimens were observed at low magnification in a tabletop scanning electron microscope (SEM, TM-1000; Hitachi, Tokyo, Japan) and with a field emission scanning electron microscope (FESEM; Hitachi S-4700, Tokyo, Japan) for details of the microstructure requiring higher magnification. Nitrogen adsorption-desorption isotherm measurements were performed on a Tristar 3000 volumetric adsorption analyzer (Micromeritics Corp, USA) in a wide pressure partial range at 77K. Specimens of N0-1500, N0-1700 and N7-1500 were used in these 
measurements; it was not possible to achieve reliable data for N7-1700 because of the very low adsorption. The Barrett-Joyner-Halenda $(\mathrm{BJH})$ method was used to determine the pore size distribution in the meso-pore region. The specific surface area was estimated by the BET method.

The 3D specimens -one for each composition/SPS treatment- were heated using a micro-torch gas burner with a butane/air mixture during $\sim 60 \mathrm{~s}$, at a fixed distance of 2 $\mathrm{cm}$ and freely left to cool down. Two different experimental setups were evaluated, in one the 3D structure was placed on a bulky metal piece and in the second, the resting piece was an insulating fiber mat (see images of the setups on the Supplementary Information, Fig. S1). The temperature on the exposed surface (square cell side) of the structures was recorded with a thermal imaging infrared camera (FLIR A325sc, USA), and the cooling temperature profiles were extracted. Parallel tests were followed for a commercial dense bulk SiC (Hexoloy S.A., Saint-Gobain, France) cut to alike dimensions of the outer $\mathrm{SiC}$ lattices and used for comparative purposes.

Structures were tested under compression using a universal testing machine (ZwickiLine Z5.0TS, Zwick-Roell, Germany) and a displacement rate of $0.5 \mathrm{~mm} \cdot \mathrm{min}^{-1}$ until crushing. The specimens were previously ground at the top/bottom surfaces (square cell-side) to ensure a homogeneous distribution of the load on the whole scaffold. Three structures were tested for each material. The strength was calculated from the peak load divided by the contact surface, and the apparent elastic modulus was estimated from the lineal section of the load/displacement plots.

\section{Results and discussion}


Water-based inks were prepared in the same way as reported in previous works [6,7], but adjusting the amount of surfactants for the present powders and compositions (N0 and N7), as detailed in Table 1. The solids content is similar for both inks, $\sim 61 \mathrm{wt} . \%$. Rheological tests show alike $\eta_{\text {app }}$ for the both inks (Fig. 1a), which display a typical shear thinning response, performing as gelled colloidal suspensions with a pseudoplastic behavior [6]. The storage modulus $\mathrm{G}^{\prime}$ that dominates at lower shear stresses is $\cong 10^{4} \mathrm{~Pa}$ for N0 (Fig. 1b) and about three times higher for the N7 ink, which also retains its value at higher stresses and, consequently, shows a higher yield stress $\left(\sigma_{\mathrm{y}}=350 \mathrm{~Pa}\right)$ than that of the N0 ink $\left(\sigma_{\mathrm{y}}=250 \mathrm{~Pa}\right)$.

Table 1.- Composition of the inks used for printing the 3D structures. The content of water only refers to the added water.

\begin{tabular}{|c|c|c|c|c|}
\hline & \multicolumn{2}{|c|}{ No } & \multicolumn{2}{c|}{ N7 } \\
\hline & $\begin{array}{c}\text { Weight } \\
(\%)\end{array}$ & $\begin{array}{c}\text { Volume } \\
(\%)\end{array}$ & $\begin{array}{c}\text { Weight } \\
(\%)\end{array}$ & $\begin{array}{c}\text { Volume } \\
(\%)\end{array}$ \\
\hline $\begin{array}{c}\text { ceramic } \\
\text { powders }\end{array}$ & 61.2 & 33.3 & 61.4 & 33.0 \\
\hline H-PEI & 3.7 & 6.3 & 3.8 & 6.5 \\
\hline L-PEI* & 3.8 & 6.3 & 3.8 & 6.3 \\
\hline MC $^{*}$ & 6.1 & 10.1 & 6.2 & 10.4 \\
\hline $\mathrm{H}_{2} \mathrm{O}$ & 25.2 & 44.0 & 24.8 & 43.8 \\
\hline
\end{tabular}

The relative lineal shrinkage (Fig. 2) of N0 structures sintered at 1500 and $1700{ }^{\circ} \mathrm{C}$ is quite small $(\leq 5 \%)$, as expected in the absence of liquid phase formation, whereas N7 structure reaches up to $\sim 28 \%$ of linear shrinkage for the $1700{ }^{\circ} \mathrm{C}$ treatment. These differences are illustrated by both images inserted in Fig. 2, also demonstrating that the structures maintain the original geometry after sintering. The filament diameter 
typically fluctuates from $\sim 290 \mu \mathrm{m}$-for both N0 structures- to values around 270 and $230 \mu \mathrm{m}$-for the N7-1500 and N7-1700 scaffolds, respectively- matching their sinterability. Obviously, the macro-porous size defined by the structure channels is correspondingly affected, typically varying from $\sim 700 \mu \mathrm{m}$ for the specimens with relative shrinkages under $10 \%$ to $\sim 500 \mu \mathrm{m}$ for the N7-1700 scaffold (see Fig. 3).

a)

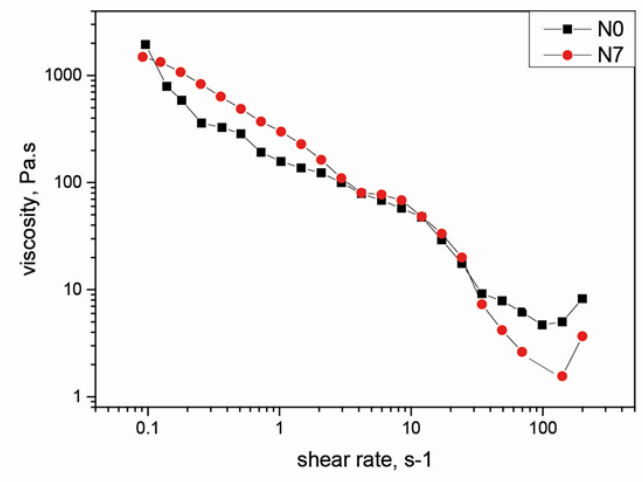

b)

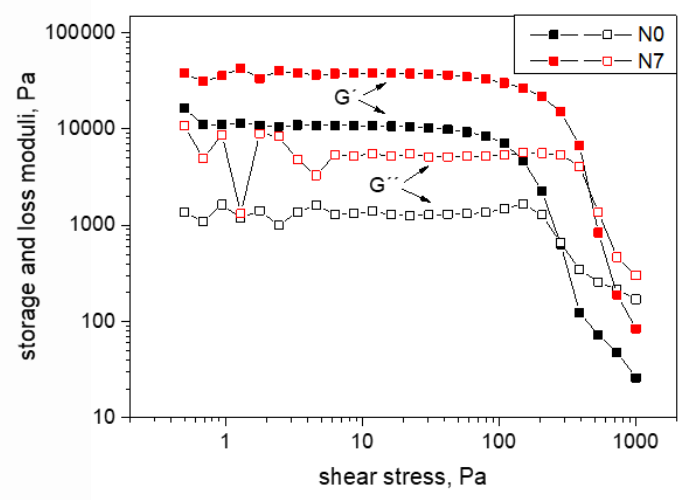

Figure 1. (a) Apparent viscosity of the inks as a function of shear rate and (b) storage $\left(\mathrm{G}^{\prime}\right)$ and loss $\left(\mathrm{G}^{\prime \prime}\right)$ moduli for both inks (N0 and N7).

Mass losses of the calcined SiC structures are relatively large (12-20\%) in consonance with the inks compositions (Table 1). For sintered structures, mass losses correlate with the treatment temperature and the presence of sintering aids in the composition (Fig. 2), being determined by both the open porosity and the increased instability of the oxide phases when the temperature rises, i.e. the $\mathrm{SiO}_{2}$ in the raw $\mathrm{SiC}$ powders, besides the $\mathrm{Al}_{2} \mathrm{O}_{3}$ and $\mathrm{Y}_{2} \mathrm{O}_{3}$ sintering aids $[20-21]$. 


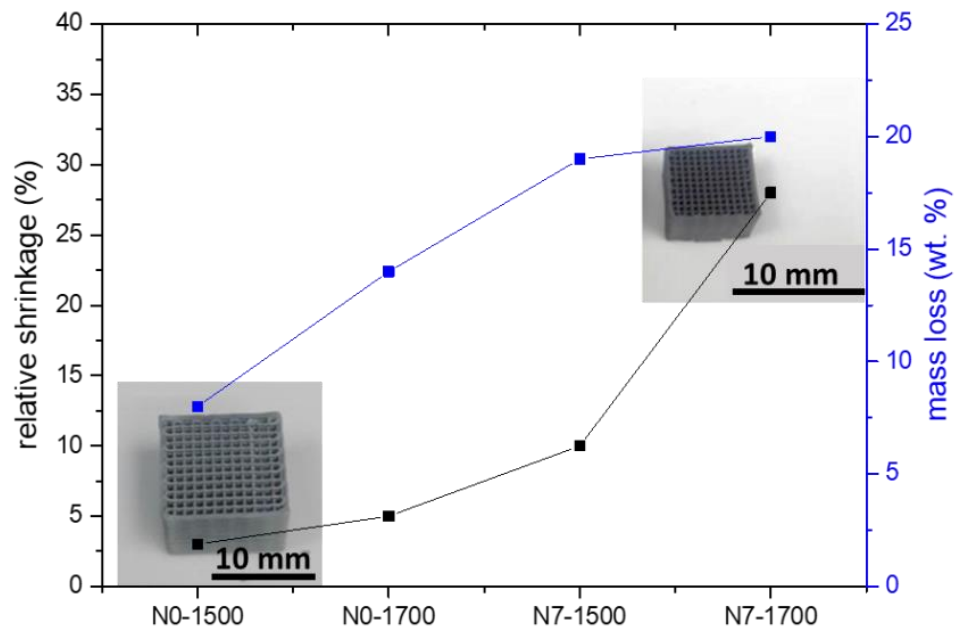

Figure 2. Data of relative shrinkage and mass loss after SPS treatments for the different $\mathrm{SiC}$ scaffolds (previously calcined at $600^{\circ} \mathrm{C}$ ) with attached images for the N0-1500 and N7-1700 structures.

All density values are compared in Fig. 4 for each specimen type. The $\rho_{\text {bulk }}$ of the scaffolds varies from $0.5-0.7 \mathrm{~g} \cdot \mathrm{cm}^{-3}$ for the N0-1500, N0-1700 and N7-1500 specimens to $\sim 1.2 \mathrm{~g} \cdot \mathrm{cm}^{-3}$ for the $\mathrm{N} 7-1700$ specimen. This two-fold increase in density denotes that the liquid phase sintering mechanism plays a significant role for $\mathrm{N} 7$ composition above $1500{ }^{\circ} \mathrm{C}[21]$. On the other hand, $\rho_{\text {app }}$ are similar for all the specimens and also close to the theoretical for each structure (Fig. 4), indicating that porosity is predominantly open and accessible. The total porosity of the structures ranges from $\sim 64 \%$ for the N7-1700 to $\sim 84 \%$ for the N0-1700 (Fig. 4). 

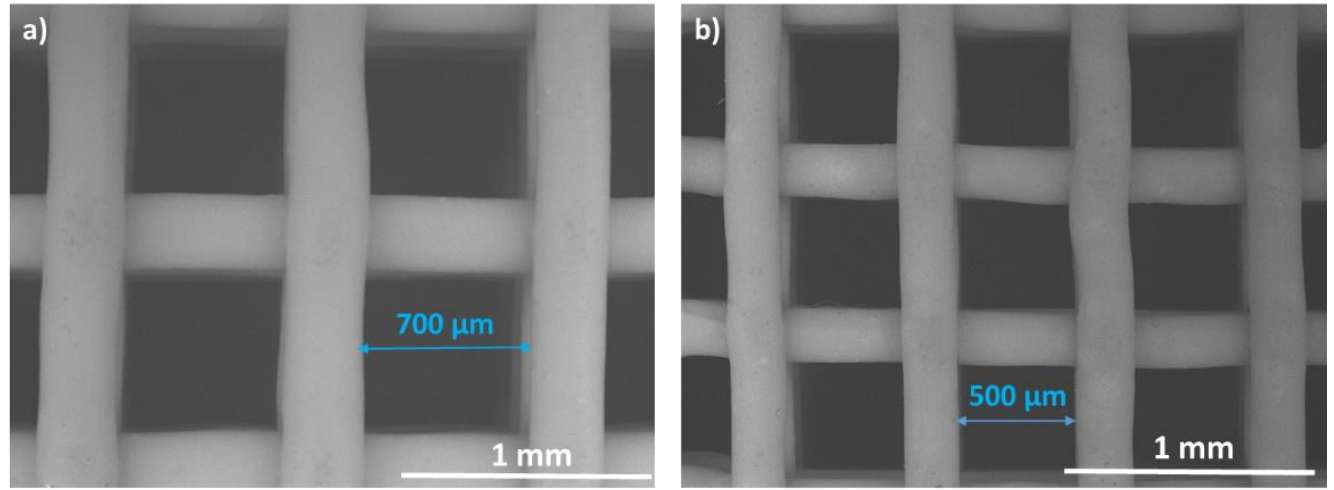

Figure 3. Typical channel sizes, i.e. macro-pores, for (a) N7-1500 and (b) N7-1700 scaffolds.

The specimen N7-1700 with the highest $\rho$ bulk shows the densest filaments as well, $\rho_{\text {strut }}$ around $2.6 \mathrm{~g} \cdot \mathrm{cm}^{-3}$, whereas the rest of the specimens exhibit strut densities in the range 1.3-1.5 $\mathrm{g} \cdot \mathrm{cm}^{-3}$ and total porosities of $\sim 80 \%$ (Fig. 4). If we compare these densities with the respective theoretical values, i.e. $3.21 \mathrm{~g} . \mathrm{cm}^{-3}$ (N0) and $3.28 \mathrm{~g} \cdot \mathrm{cm}^{-3}$ (N7) we observe that for the N0 (both temperatures) and N7-1500 structures the densities of the skeletons are about $40-46 \%$ of their theoretical densities, whereas for SiC N7-1700 structure reaches $\sim 80 \%$ of the theoretical density. 


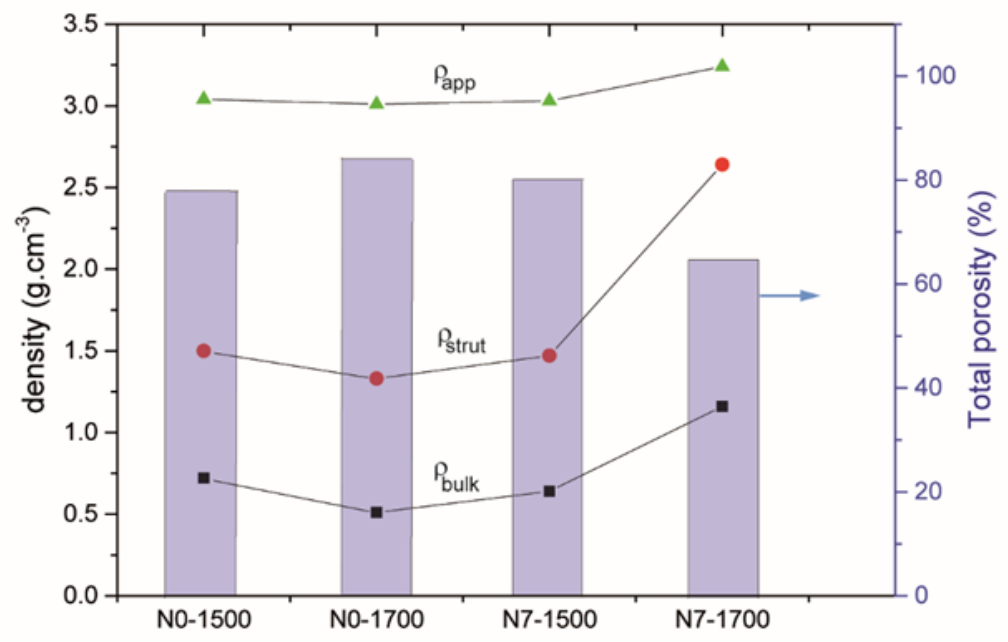

Figure 4. Values for the bulk, strut and apparent densities of the different scaffolds, together with the total porosity of the whole structures.

The variation of the SiC grain size is also remarkable, as it can be observed in the fracture surface images of the different skeletons (Fig. 5). The microstructures of N0 and $\mathrm{N} 7$ scaffolds (both treated at $1500{ }^{\circ} \mathrm{C}$ ) are very fine, with grain sizes in the range 50-100 nm (Fig. 5a,c), alike the size of the original powders. Conversely, the materials treated at $1700{ }^{\circ} \mathrm{C}$ (Fig. 5b,d) reveal the occurrence of notable grain growth, with sizes in the 0.5-3.0 $\mu \mathrm{m}$ range, but attributable to different mechanisms for N0 and N7. In fact, the growth of faceted $\mathrm{SiC}$ crystal (Fig. 5b) reveals the predominance of a gas-phase sintering mechanism (evaporation-condensation) for the N0-1700 specimen; whereas for the N7-1700 scaffold, a microstructure of equiaxed homogenous grains (Fig. 5d), typical of liquid phase sintered $\mathrm{SiC}$ materials though a solution-precipitation-grain growth mechanism is observed [23]. Accordingly, the sizes of pores in the struts should be also affected as is perceived in the SEM micrographs (Fig. 5). Actually, the gasphase $\mathrm{SiC}$ grain growth reveals a quite open microstructure in the struts of the N0-1700 
with partially connected crystals and large size pores as compared to the N0-1500 and N7-1500 scaffolds.
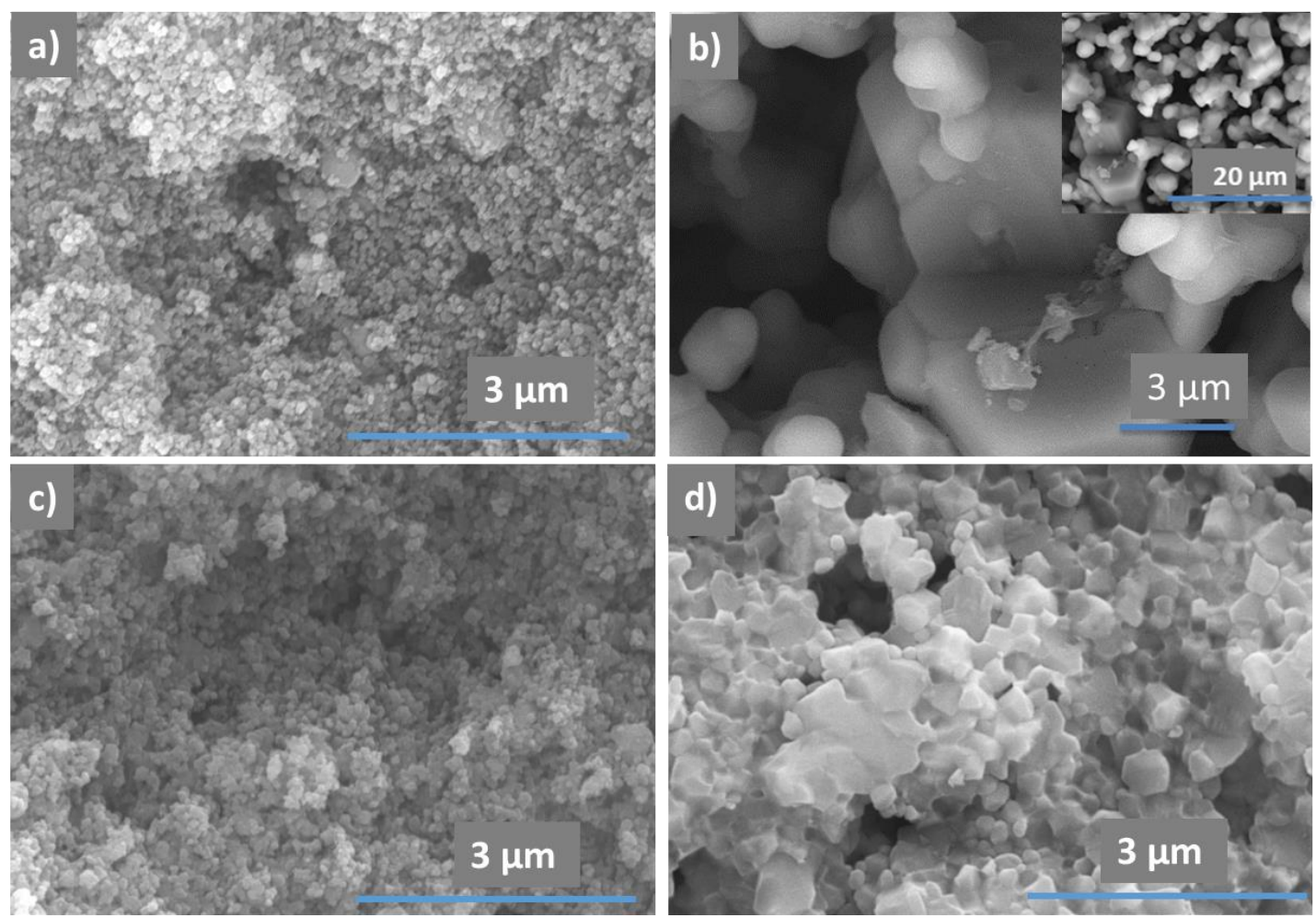

Figure 5. Typical microstructures on the fracture surface of a filament in the scaffolds of a) N0-1500, b) N0-1700, c) N7-1500 and d) N7-1700.

According to these observations, the $\mathrm{N}_{2}$ adsorption-desorption isotherms (Fig. 6a) of the scaffolds show hysteresis for N0-1500 and N7-1500, which is an indication of the presence of meso-pores; whereas, the N0-1700 scaffold does not show any mesoporosity in the struts. The plot of the pore size distribution (Fig. 6b), according to the $\mathrm{BJH}$ model, indicates the occurrence of a peak of meso-pores at $30 \mathrm{~nm}(\mathrm{~N} 0-1500)$ and $40 \mathrm{~nm}$ (N7-1500 N0-1700 is a very interesting structure since, despite showing larger pore pore sizes $(>70 \mathrm{~nm}$ ) in the struts, it still exhibits porosity at different scales (from 
a few to hundreds of $\mu \mathrm{m}$, Fig. 7). Moreover, it presents the highest porosity among the structures (Fig. 4)

Specific surface area and total volume of pores with sizes between 1.8 and $300 \mathrm{~nm}$ as well as the average pore diameter of meso-pores are reflected in Table 2. It is interesting to note that $\mathrm{S}_{\mathrm{BET}}$ for $\mathrm{N} 0-1500$ is close to the value of the original powders $\left(35-40 \mathrm{~m}^{2} \cdot \mathrm{g}^{-}\right.$ ${ }^{1}$ ), whereas for N7-1500 decreases to half that value and even more abruptly for the N01700. In consonance, the total volume of pores under $300 \mathrm{~nm}$ is higher $\left(0.078 \mathrm{~cm}^{3} \cdot \mathrm{g}^{-1}\right)$ for N0-1500 specimens than for the others presented in this work. The average mesopore size for the N0-1500 struts is about 1/3 the original size of the SiC powders, being therefore coincident with the rule that pore size is within a half and a fifth of the powders size [4].

a)

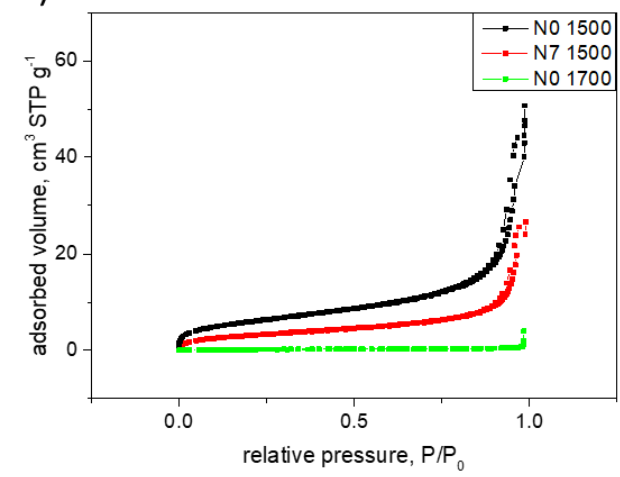

b)

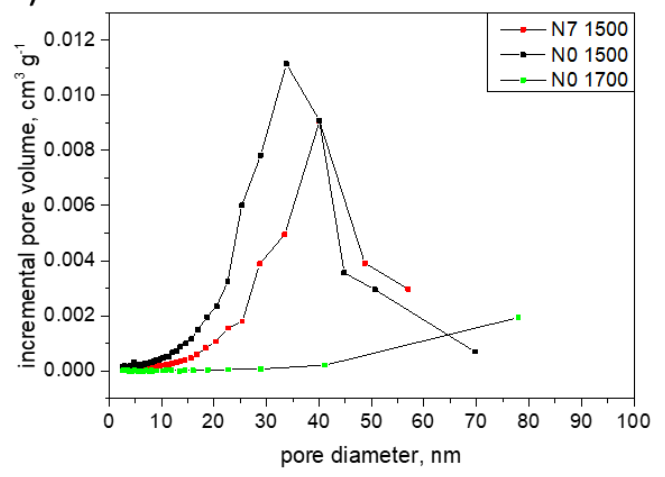

Figure 6. (a) $\mathrm{N}_{2}$ adsorption/desorption isotherms of both compositions showing hysteresis for the $1500{ }^{\circ} \mathrm{C}$ treated scaffolds and (b) BJH pore size distribution calculated from the desorption branch. 


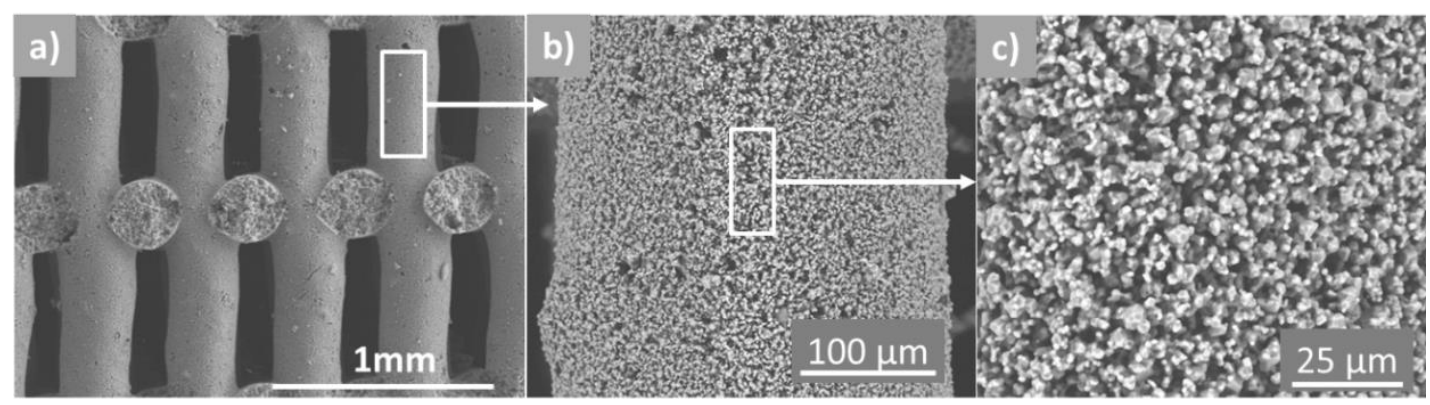

Figure 7. Images of N0-1700 scaffold showing a representative view of large channels (a), the surface of a rod with macro-pores (b) and the faceted SiC grains in the surface of the rod at higher magnification (c).

Table 2. Specific surface area, total volume of pores between 1.7 and $300 \mathrm{~nm}$, and average diameter for meso-pores (BJH desorption) for the indicated structures.

$$
\text { N0-1500 N0-1700 N7-1500 }
$$

\begin{tabular}{l|lll}
\hline $\mathrm{S}_{\mathrm{BET}}\left(\mathrm{m}^{2} \cdot \mathrm{g}^{-1}\right)$ & 21.5 & 0.8 & 12.2 \\
volume of pores & 0.078 & 0.0027 & 0.038 \\
$\left(\mathrm{~cm}^{3} \mathrm{~g}^{-1}\right)$ & & & \\
$\mathrm{d}(\mathrm{nm})$ & 17 & 50 & 27
\end{tabular}

These materials present slight differences regarding the phase analysis, All the structures consist of a mixture of the cubic phase, $\beta$-SiC (3C), and two hexagonal polytypes, $\alpha-\mathrm{SiC}$, while both N7 structures show, in addition, the presence of yttrium aluminum monoclinic, $\mathrm{YAM},\left(\mathrm{Al}_{2} \mathrm{Y}_{4} \mathrm{O}_{9}\right)$, in agreement with the occurrence of liquid phase sintering process that predicts the precipitation of different $\mathrm{Y}$-aluminate phases depending on the SPS sintering conditions [24]. 
On the other hand, it has recently been shown that porous nano-sized $\mathrm{SiC}$ materials (around $60 \%$ porosity and $35 \mathrm{~nm}$ of grain size) possess low thermal conductivity values $\left(\sim 2 \mathrm{~W} \cdot \mathrm{m}^{-1} \cdot \mathrm{K}^{-1}\right)$, effect that authors attributed to the existence of a high density of stacking faults and, accordingly, their potential application as thermal insulator was claimed[25]. However, for these kinds of open cell structures radiative and convective heat transfer to their surroundings may be prevailing over conduction [26]. To get an simple appraisal of their heat transfer behavior, present 3D structures were subjected to a torch flame that produced a rapid heating on the exposed surface, and the corresponding free cooling of the surface was recorded as a function of time. The cooling profiles for each structure are plotted in Fig. 8 where the analogous cooling profile for dense Hexoloy material is included (these data correspond to tests where specimens rested on a metal piece; see Fig. S1). It should be mentioned that no signs of degradation were evidenced for any of the tested materials and that the maximum temperature achieved on the exposed surface $\left(\mathrm{T}_{0}\right)$ depended on the particular material. Certainly, values of $\mathrm{T}_{0} \sim 1000{ }^{\circ} \mathrm{C}$ were reached for the $3 \mathrm{D}$ structures with porosities around $80 \%$ (i.e. for N0-1500, N0-1700, N7-1500, see Fig. 4) after exposure times of 60 s, whereas a relatively lower temperature $\left(800^{\circ} \mathrm{C}\right)$ was achieved for the N7-1700 structure in agreement to its lower porosity (Fig. 4). Moreover, an even lower peak temperature $\left(\sim 500{ }^{\circ} \mathrm{C}\right)$ was measured for the dense $\mathrm{SiC}$ material, which under the given experimental heating conditions clearly reached a limit temperature because of the higher heat dissipation by conduction to the surroundings (namely the metal the bench), as compared to the 3D structures. Accordingly, the highly-porous structures demonstrated much lower thermal inertia. 
It should be mentioned that for similar tests but for specimens resting on the insulating fiber mat, a raise in the peak temperatures of $250^{\circ} \mathrm{C}$ was observed for the Hexoloy $\mathrm{SiC}$ material, but certainly lower for the porous $3 \mathrm{D}$ materials $\left(\sim 100^{\circ} \mathrm{C}\right)$, as it can be seen in the Supplementary Information (Table S1 and Fig. S2). This result, compared to the above reported test, indicates that heat dissipation by conduction notably decreases for the dense $\mathrm{SiC}$ when using an insulating support that occurs. In fact, the differences in the limit temperatures achieved for the two kinds of materials -with structured porosity and dense- reduces from about $500{ }^{\circ} \mathrm{C}$ to $300{ }^{\circ} \mathrm{C}$ when conduction is mostly suppressed (Table S1).

Despite the non-linearity of the complete heat transfer equation due to the radiative term, it is commonly found that third-order exponential functions -having different time constants and amplitudes- fit quite well the cooling of an object [27]. In effect, the cooling profiles for present 3D the structures (Fig. 8) showed good fitting to expressions of the type:

$T(t)=y_{0}+A_{1} e^{-t / a}+A_{2} e^{-t / b}$ eq. [1]

with two exponential terms. Fitting parameters were relatively similar for all the 3D SiC structures (Table 3). The first exponential dominates in the high temperature range where the radiative dissipation mainly governs. However, for temperatures between 500 and $550{ }^{\circ} \mathrm{C}$, the first exponential fades and the second exponential solely dominates, as it can be seen in Fig. 9 for the N0-1500 structure, which is the typical functional form for the Newton's cooling law associated to convective cooling. Conversely, for the dense $\mathrm{SiC}$ material, the cooling curve was well fitted just using the convection term (Table 3). Larger values of the pre-exponential term, A1, are found for N0-1500 and N7-1500 scaffolds, which infers a higher contribution of the radiative term for the 
materials with meso-porosity; whereas, the densest material (N7-1700) showed significantly lower contribution of the radiative term.

a)

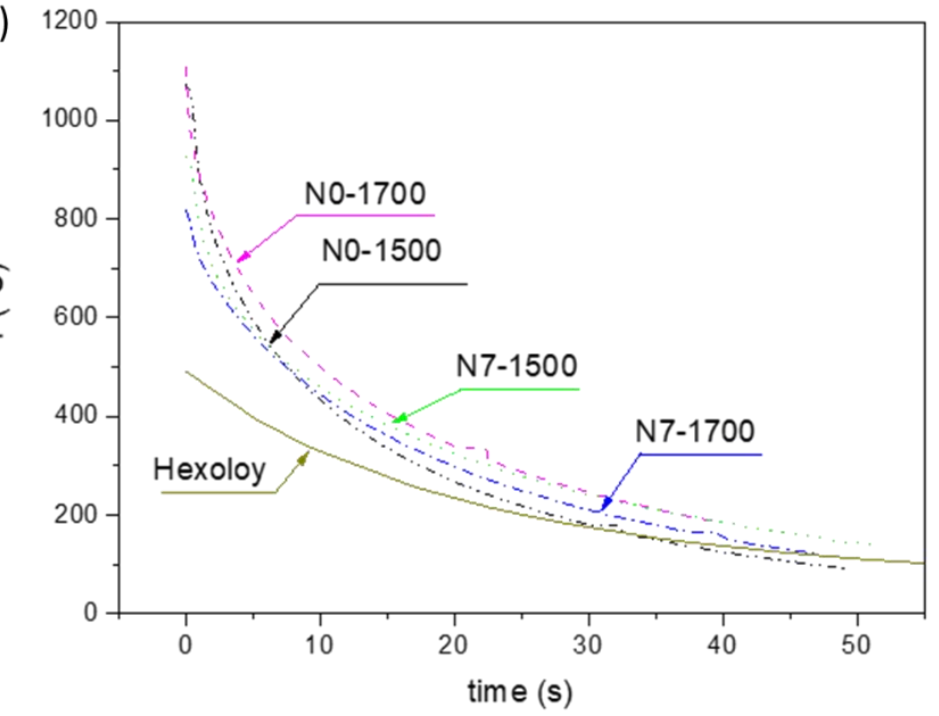

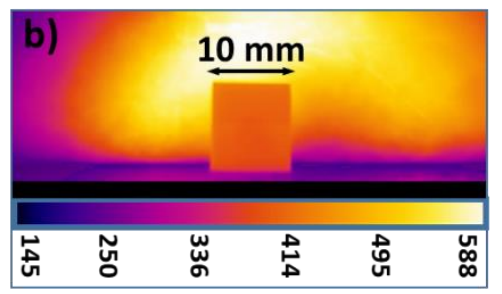

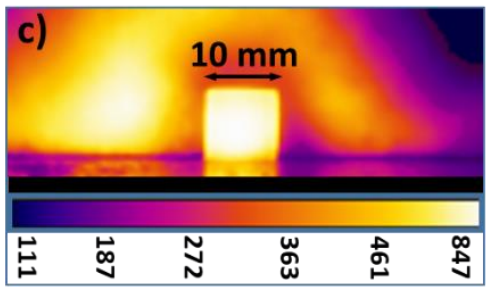

Figure 8. a) Plot of cooling profiles for the SiC structures and the dense material after exposure to the flame torch (specimens resting on brass). Examples of thermographic images after $5 \mathrm{~s}$ of cooling of b) dense SiC Hexoloy and c) N7-1500.

Furthermore, the weight of the convection term in eq. [1] is quite similar for all the scaffolds but significantly lower than for the dense $\mathrm{SiC}$ (see parameters $\mathrm{A} 2$ and $\mathrm{b}$ in Table 3). It should be pointed out that, for the latter material, the cooling profile from a temperature $\left(\sim 800{ }^{\circ} \mathrm{C}\right)$, i.e. when an insulating support was used, is perfectly fitted with just a convection term, (see Figure S2 of the Supplementary Information). Therefore, these highly-porous $\mathrm{SiC}$ structures, especially those containing meso-porosity, demonstrate extraordinary thermal dissipation and low thermal inertia.

Table 3. Fitting parameter for eq. [1] for each material type 


\begin{tabular}{l|lllll}
\multicolumn{7}{c|}{} & N0-1500 & N0-1700 & N7-1500 & N7-1700 & HEXOLOY \\
\hline y0 & 63 & 121 & 82 & 64 & 69 \\
$\mathrm{~A}_{1}$ & 367 & 246 & 270 & 115 & - \\
$\mathrm{a}$ & 1.6 & 1.5 & 1.7 & 1.3 & - \\
$\mathrm{A} 2$ & 691 & 691 & 597 & 641 & 1040 \\
$\mathrm{~b}$ & 16.4 & 17.3 & 22.5 & 19.9 & 21.6
\end{tabular}

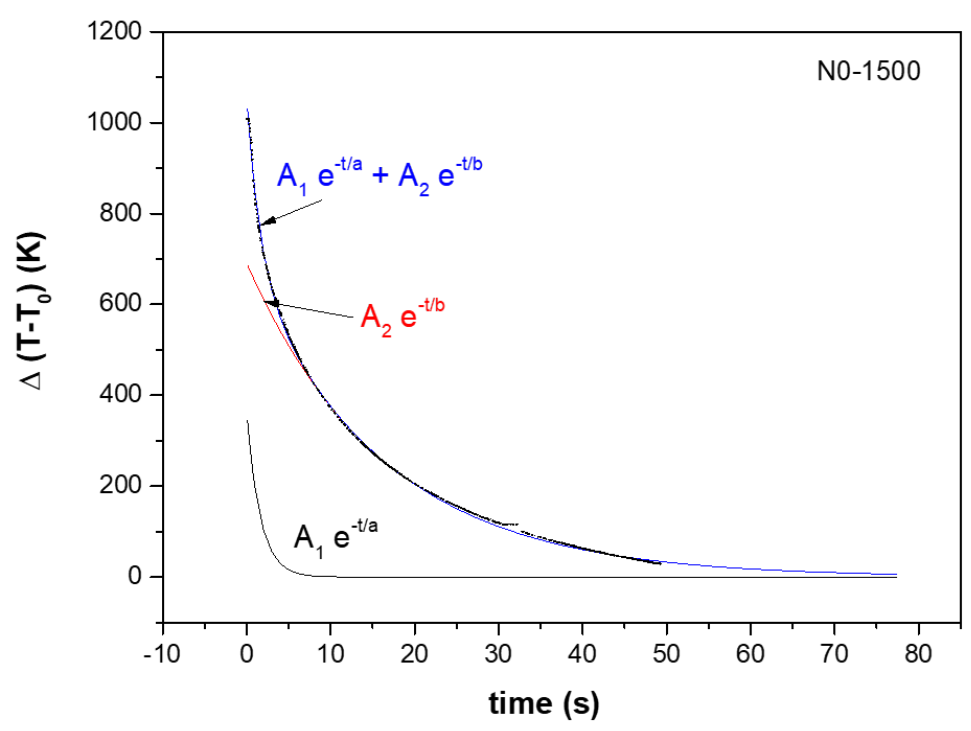

Figure 9. Cooling profile of N0-1500 structure showing experimental points and the second order exponential fitting curve. Both exponential terms are separately plotted to contrast the different regimes of dominance.

For highly porous structures as the present $(60-85 \%)$ is imperative to attain certain robustness. Hence, typical loading curves for the different structures are compared in 
Fig. 10, where the higher stiffness and loading capacity of N7-1700 is perceived, whereas the rest of the structures show higher deformation up to fracture. Peaks in the stress/strain plots of N7 structures are indicative of single failure events, although structures still maintain their bearing capability until total collapse.

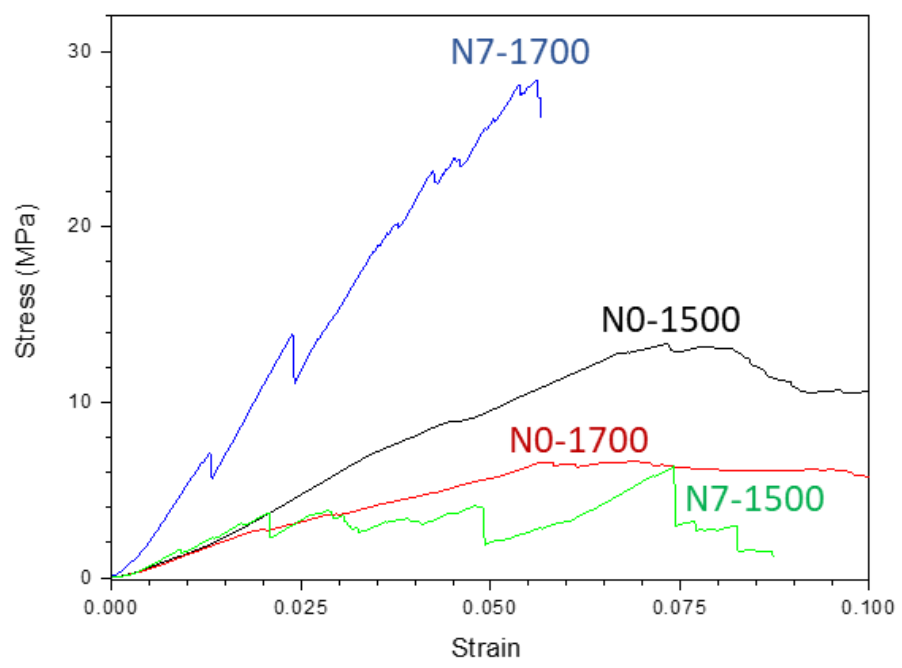

Figure 10. Representative stress-strain curves under compression for the 3D SiC structures

Compressive strength and elastic modulus data are correspondingly represented as a function of $\rho_{\text {bulk }}$ for all the tested specimens (Fig. 11). Both properties increase with density as expected. Lines in the plots of Fig. 11 represent polynomial regression fitting of degree 1.5 for strength and quadratic for the elastic modulus, which are frequent for cellular materials [28].

Strengths are above $5 \mathrm{MPa}$ for all the structures, with values up to around 20-30 MPa for the structure with of $\rho_{\text {bulk }}=1.1 \mathrm{~g} \cdot \mathrm{cm}^{-3}$. Average strengths in the range $1-16 \mathrm{MPa}$ for porosities of 75-86\% [28-31] and in the range 20-30 MPa for porosities of 55-60\% [3132] have been reported for cellular SiC. Compressive strength values for a different 
highly porous cellular $\mathrm{SiC}$ materials, fabricated by diverse routes (freeze casting, replica of polymeric foams with a slurry or graphite filled polymeric precursors), are including in plot of Fig. 11a). A straightforward comparison of present hierarchical structures (N0-1500 and N7-1700) and cellular SiC materials of comparable density (Fig. 11a) indicates that having porosity at different scales (meso- and macro-pores) has a positive effect on the compressive strength.

a)

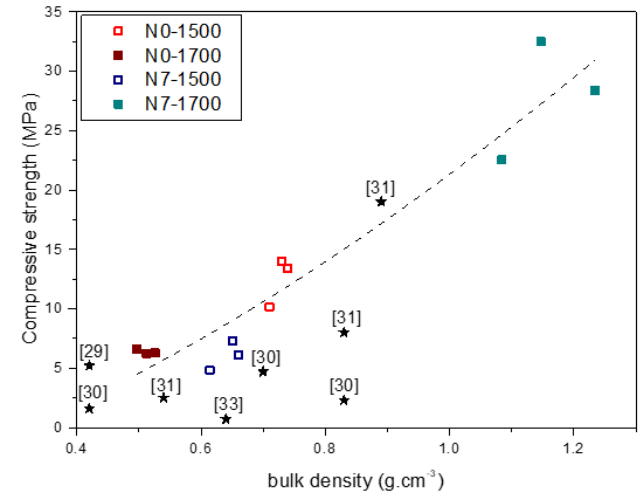

b)

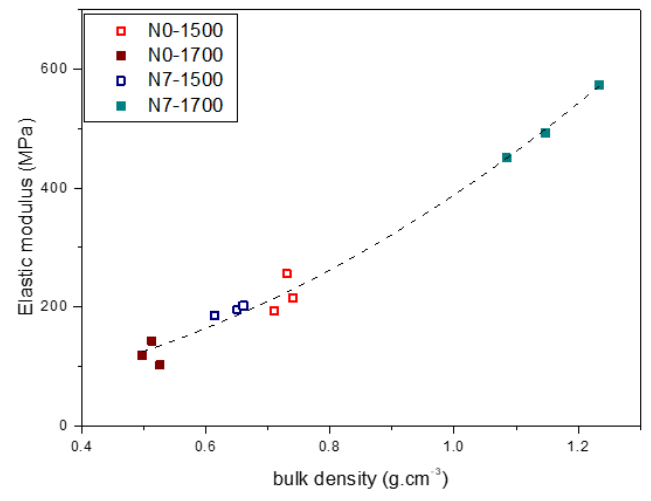

Figure 11. a) Compression strengths and b) elastic modulus for the 3D structures.

Dotted lines correspond to polynomial regression fitting of degree 1.5 for strength and quadratic for the modulus. Data points ( $*$ ) for different highly porous cellular SiC materials are also plotted in a) with indication of the corresponding work.

Summarizing, we have demonstrated that the partial sintering of 3D filament printed $\mathrm{SiC}$ structures is a basic effective route to achieve light $\mathrm{SiC}$ materials (60-85\% porosity) with a hierarchical pore structure, of macro-pores of hundreds of $\mu \mathrm{m}$ defined by $3 \mathrm{D}$ construct and much smaller size pores, including meso-pores in the struts for the s lower sintering temperatures $\left(1500{ }^{\circ} \mathrm{C}\right)$. The total volume of pores can practically be controlled by selecting the sintering aids and the temperature. Having porosity at 
different scales (meso- and macro- level) definitively benefits the strength and thermal dissipation performance of present highly porous 3D structures. This family of materials is suitable for quite a number of applications and, particularly, as filters/absorbers, gas burners or in fields as catalysis and thermal protection/dissipation.

\section{Acknowledgments}

This work was supported by MINECO/FEDER, UE with project MAT2015-67437-R.

The experimental support of Maria Calvo Martin is recognized.

\section{References}

1. A. R. Studart, U. T. Gonzenbach, E. Tervoort, L. J. Gauckler, Processing routes to macroporous ceramics: a review. J. Am. Cerm. Soc. 89, 1771-89, (2006).

2. J-H Eom, Y-W Kim, S. Raju Processing and properties of macroporous silicon carbide ceramics: A review, Journal of Asian Ceramic Societies, 1, 220-42, (2013).

3. P. Colombo, C. Vakifahmetoglu and S. Costacurta, Fabrication of ceramic components with hierarchical porosity, J. Mat. Sci., 45, 5425-5455, (2010).

4. T. Ohji, Fukushima. Macro-porous ceramics: processing and properties. International Materials Reviews, 55, 115-135, (2012).

5. M. Fukushima, Y. Zhou, H. Miyazaki, Y. Yoshizawa, K. Hirao. Microstructural characterization of porous silicon carbide membrane support with and without alumina additive, J. Am. Ceram. Soc., 89 [5], 1523-1529 (2006) 
6. K. Cai, B. Román-Manso, J. E. Smay, J. Zhou, M. I. Osendi, M. Belmonte, P. Miranzo. Geometrically complex silicon carbide structures fabricated by robocasting. J. Am. Ceram. Soc., 95, 2660-2666 (2012).

7. B. Román-Manso, A de Pablos, M. Belmonte, M. I. Osendi, P. Miranzo Microstructural designs of spark-plasma sintered silicon carbide ceramic scaffolds, Boletín de la Sociedad Española de Cerámica y Vidrio 53, 93-100, (2014).

8. N. A. Fleck, V. S. Deshpande, M. F. Ashby, Micro-architectured materials: past, present and future. Proc. R. Soc. A 466, 2495-2516 (2010).

9. D. Arcos, M. Vallet-Regí. Sol-gel silica-based biomaterials and bone tissue regeneration. Acta Biomaterialia, 6, 2874-2888 (2010).

10. J. Liu, G. Jiang, Y. Liu, J. Di, Y. Wang, Z. Zhao, et al. Hierarchical macromeso-microporous zsm-5zeolite hollow fibers with highly efficient catalytic cracking capability. Sci. Reports 4:7276 (2014)

11. C. Minas, D. Carnelli, E. Tervoort, A. R. Studart, 3D printing of emulsions and foams into hierarchical porous ceramics, Adv. Mater., 28, 9993-9999, (2016).

12. J. Maurath, N. Willenbacher, 3D printing of open-porous cellular ceramics with high specific strength. J. Eur. Ceram. Soc. 37, 4833-4842, (2017).

13. L. Chen, X. Tang, P. Xie, J. Xu, Z. Chen, Z. Cai et al., 3D printing of artificial leaf with tunable hierarchical porosity for $\mathrm{CO}_{2}$ photoreduction. Chem. Mater. 30, 799-806 (2018).

14. M. Fukushima, Y. Yoshizawa, P. Colombo. Decoration of ceramic foams by ceramic nanowires via catalyst-assisted pyrolysis of preceramic polymers. J. Am. Ceram. Soc., 1-7 (2012). 
15. C. Ferraro, E. Garcia-Tuñon, V. G Rocha, S. Barg, M. D Fariñas, et al Light and Strong SiC Networks. Adv. Funct. Mater., 26: 1636-1645 (2016).

16. B. Román-Manso, S. M Vega-Díaz, A. Morelos-Gómez, M. Terrones, P. Miranzo, M. Belmonte. Aligned carbon nanotube/silicon carbide hybrid materials with high electrical conductivity, superhydrophobicity and superoleophilicity .Carbon 80, 120-126 (2014).

17. A. Quintanilla, J.A. Casas, P. Miranzo, M.I. Osendi, M. Belmonte. 3D-Printed Fe-doped silicon carbide monolithic catalysts for wet peroxide oxidation processes. Applied Catalysis B: Environmental 235, 246-25 5(2018).

18. E. Garcia, P. Miranzo, M. I. Osendi. The use of ceramic materials in the gas burner technology, in Recent Research Development Materials Science vol. 4 (2003), pp 737-754, Research Signpost, Editor: S. G. Pandalai. ISBN: 81-271-0022-6.

19. G. Bianchi, S. Gianella, A. Ortona. Design and Additive Manufacturing of Periodic Ceramic Architectures. J. Ceram. Sci. Tech., 08 [01] 59-66 (2017).

20. L. S. Sigl, and H.-J. Kleebe, Core/Rim Structure of Liquid-Phase-Sintered Silicon Carbide. J. Am. Ceram. Soc., 76, 773-776 (1993).

21. A. H. Heuer, V. L. K. Lou, Volatility Diagrams for Silica, Silicon Nitride, and Silicon Carbide and Their Application to High-Temperature Decomposition and Oxidation, J. Am. Ceram. Soc. 73, 2789-2803 (1990).

22. B. Román-Manso, F.M. Figueiredo, B. Achiaga, R. Barea, D. Pérez-Coll, A. Morelos-Gómez, et al., Electrically functional 3D-architectured graphene/SiC composites, Carbon 100, 318-328 (2016). 
23. H. Xu. T. Bhatia, S. A. Deshpande, N. P. Padture, A. L. Ortiz, and F. L.

Cumbrera, Microstructural evolution in liquid-phase-sintered SiC: I, effect of starting

SiC Powder. J. Am. Ceram. Soc., 84 [7] 1578-84 (2001).

24. B. Román-Manso, M. Belmonte, M. I. Osendi, P. Miranzo, Effects of Current

Confinement on the Spark Plasma Sintering of Silicon Carbide Ceramics, J. Am. Ceram. Soc., 98 2745-2753 (2015).

25. P. Wan, Z. Wu, H. Zhang, L.Y. Gao, J. Wang, Porous nano-SiC as thermal insulator: wisdom on balancing thermal stability, high strength and low thermal conductivity, Mater. Res. Lett. 4 104-111 (2016).

26. T. Fend, D, Trimis, R Pitz-Paal, B. Hoffschmidt, O. Reuter. Thermal properties in Cellular Ceramics: Structure, manufacturing, properties and applications. M.

Scheffler, P. Colombo (Eds), Wiley-VCH Verlag GmbH \& Co. Weinheimm 2005, pp 342-360.

27. M Vollmer. Newton's law of cooling revisited Eur. J. Phys. 30, 1063-1084, (2009).

28. M.R. Nangrejo, M.J. Edirisinghe. Porosity and Strength of Silicon Carbide Foams Prepared Using Preceramic Polymers. J. Porous Mater., 9, 131-140, (2002).

29. M. Fukushima, M. Nakata, Y. Zhou, T. Ohji and Y. Yoshizawa, Fabrication and properties of ultra-highly porous silicon carbide by the gelation-freezing method. J. Eur. Ceram. Soc., 30, 2889-2896, (2010).

30. B.H. Yoon, E.J. Lee and H.E. Kim, In Situ Synthesis of Porous Silicon Carbide (SiC) Ceramics Decorated with SiC Nanowires J. Am. Ceram. Soc., 90, 1753-1759, (2007). 
31. J.H. Eom, Y.W. Kim, C.B. Park and C. Wang, Effect of forming methods on porosity and compressive strength of polysiloxane-derived porous silicon carbide ceramics. J. Ceram. Soc. Jpn., 120, 199-203, (2012).

32. C. Polzin, D. Günther, H. Seitz. 3D printing of porous $\mathrm{Al}_{2} \mathrm{O}_{3}$ and $\mathrm{SiC}$ ceramics, J. Ceram. Sci. and Techn., 6, 141-146, (2015).

33. F. Chen, Y. Yang, Q. Shen, L. Zhang. Macro/micro structure dependence of mechanical strength of low temperature sintered silicon carbide ceramic foams.

Ceramics International 38, 5223-5229, (2012). 


\section{Supplementary Information}

\section{Highly- porous hierarchical SiC structures obtained by filament printing and partial sintering}

Alberto Gómez, Juan Jose Moyano, B. Román-Manso*, M. Belmonte, P. Miranzo, M. I. Osendi

Instituto de Cerámica y Vidrio, CSIC. Campus Cantoblanco. 28049 Madrid. Spain

Results on the heating/cooling tests for the 3D SiC structures and a dense SiC (Hexoloy, Saint Gobain) are shown below.

All specimens are of similar dimensions and outer geometry. The figures S1, S2 and Table S1 provide information on the two experimental setups, the peak temperatures reached after heating with the micro-torch for a 3D structure and the dense $\mathrm{SiC}$, and a comparison of the cooling profiles of the dense $\mathrm{SiC}$ for both conditions (metallic or insulating bench)
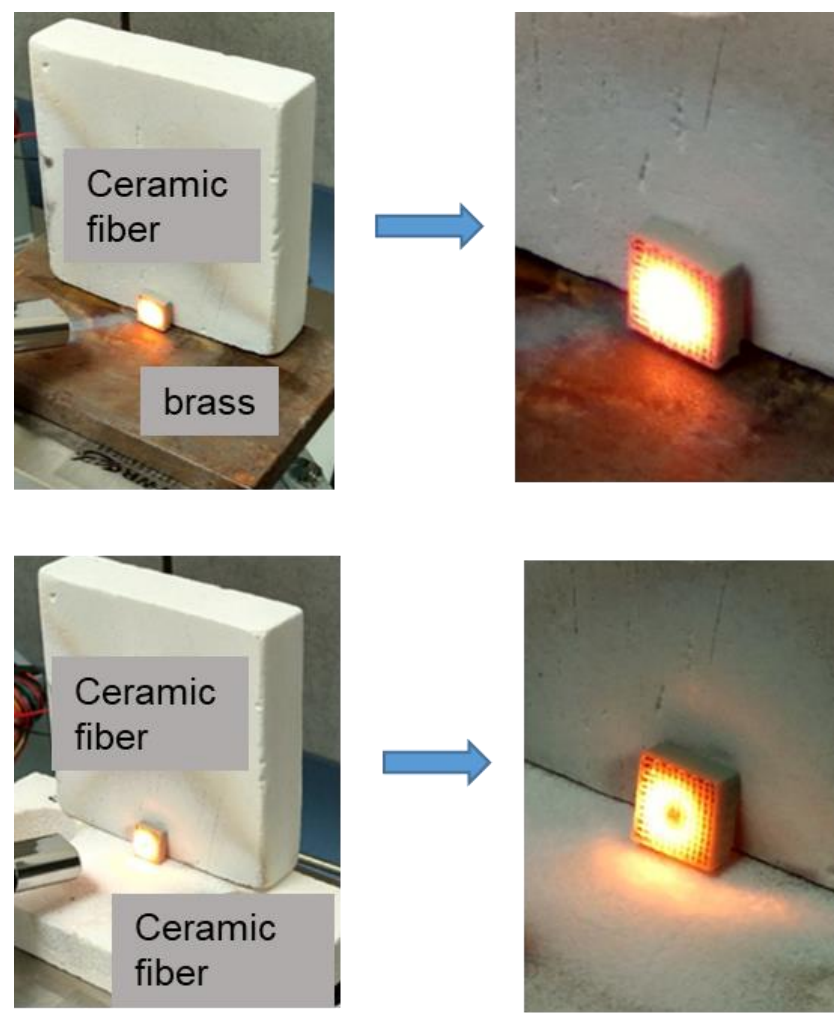

Figure S1. Images of the experimental setup for the heating experiments using the micro-torch. On the top the 3D SiC specimen (N0-1500) rests on a brass piece, whereas on the bottom it seats on a ceramic fiber mat. Rest of the conditions remained equal. 
Table S1. Comparison of peak temperatures achieved in the 3D SiC structure (N0-1500) and the dense $\mathrm{SiC}$ after heating with a micro-torch for 60 s for both experimental setups shown in Fig. S1.

\begin{tabular}{|c|c|}
\hline Specimen & Peak temperature $\left({ }^{\circ} \mathrm{C}\right)$ \\
\hline N0-1500 & 1090 \\
\hline N0-1500* & 1190 \\
\hline Hexoloy & 520 \\
\hline Hexoloy* & 770 \\
\hline
\end{tabular}

*Specimens tested over insulting fiber mat

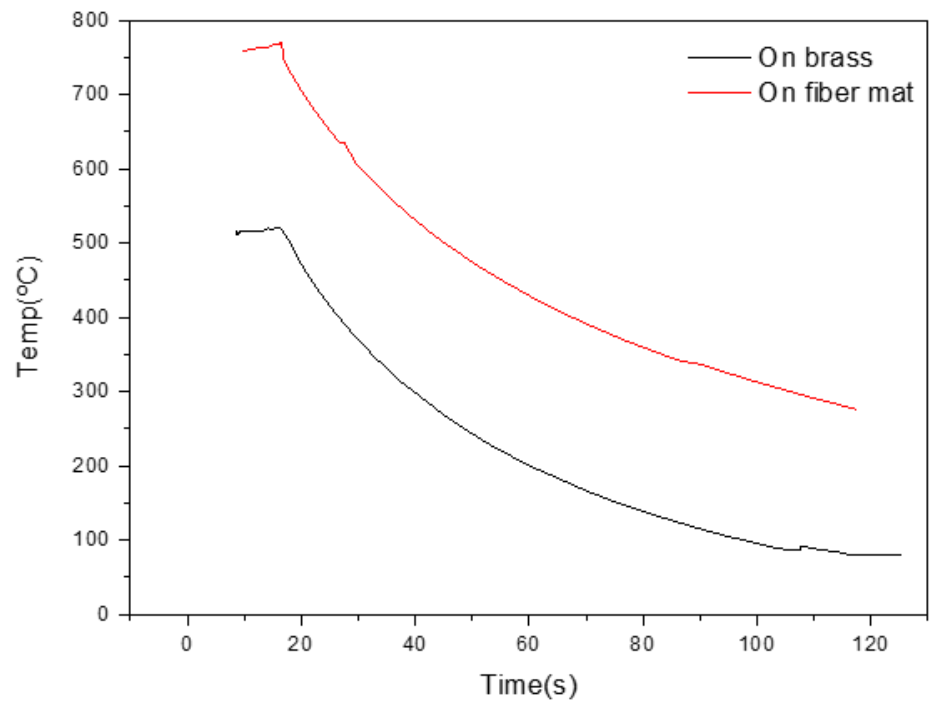

Figure S2. Cooling profiles for dense SiC (Hexoloy) for the two different experimental setups. Around $250^{\circ} \mathrm{C}$ higher peak temperature is observed for the specimen resting on the insulting fiber, but the functional forms are equal as curves can be superimposed . 